\title{
Increasing Boarding Lost Time at Regular Bus Stops during Rainy Conditions: A Case Study
}

\author{
Margarita Novales, Alfonso Orro, José-Benito Pérez-López, Jorge Feal, \\ and Miguel R. Bugarín \\ Universidade da Coruña, Group of Railways and Transportation Engineering, Spain
}

\begin{abstract}
Inclement weather conditions affect the behavior of travelers and transportation system operations. Understanding this influence can help improve operational planning schemes for any mode of transport, especially for buses. One of the factors that can be affected by rainfall is the time expended by a passenger from the moment a bus opens its doors until he/she boards the bus. This time is known as "boarding lost time" (BLT), and it was first introduced in the latest edition of the Transit Capacity and Quality of Service Manual (TCQSM). TCQSM only considers BLT for bus rapid transit (BRT) stations with more than one berth. Weather conditions are not considered when calculating the current BLT for a BRT system, given the provision of protective shelters over the entire boarding area of such stations. Furthermore, recommendations with regard to BLT for regular bus stops have not been provided. This paper presents analyses of BLT for a two-berth regular bus stop under different rainy conditions. The findings demonstrate that the increment in BLT between Berth 2 and Berth 1 under heavy rainfall is significantly higher than in the absence of rainfall.
\end{abstract}

Keywords: Boarding lost time, weather effect, dwell time, transit capacity, bus stops

\section{Introduction and Literature Review}

The purpose of this study was to analyze the influence of rainy weather conditions on boarding lost time (BLT) and consequently the dwell time (DT) at regular bus stops.

The concept of DT has been used for decades. Muzyka (1975) utilized the distribution of DT in simulations. Levinson (1983) collated and presented dwell times based on surveys conducted across a number of US cities in 1980. A review of initial DT measures can be found in Dueker, Kimpel, and Strathman (2004). In the Highway Capacity Manual (TRB 1985), DT is defined as "the time in seconds that a transit vehicle is stopped for the purpose of serving passengers. It includes the total passenger service time plus the time needed to open and

(C) 2021 Margarita Novales, Alfonso Orro, José-Benito Perez-López, Jorge Feal, and Miguel R. Bugarin https//doi.org/10.5038/2375-0901.23.1.4

ISSN: 1077-291X | Licenced under Creative Commons License Attribution - Noncommercial 4.0

The Journal of Public Transportation is published by the Center for Urban Transportation Research at the University of South Florida 
close doors." This definition was retained in the second edition of the Transit Capacity and Quality of Service Manual (TCQSM) (TRB 2003) as "the time required to serve passengers at the busiest door, plus the time required to open and close the doors." Therefore, the proposed equation for the calculation of DT is as follows:

$$
t_{d}=P_{a} t_{a}+P_{b} t_{b}+t_{o c}
$$

where $t_{d}=$ average dwell time (s); $P_{a}=$ number of alighting passengers per bus through the busiest door (p); $t_{a}=$ alighting passenger service time $(\mathrm{s} / \mathrm{p}) ; P_{b}=$ number of boarding passengers per bus through the busiest door (p); $t_{b}=$ boarding passenger service time $(\mathrm{s} / \mathrm{p})$; and $t_{o c}=$ door opening and closing time (s).

Subsequently, Jaiswal (2010) and Jaiswal, Bunker, and Ferreira (2010) included the concept of BLT in dwell time, although they referred to BLT as "bus lost time" and defined it as "the waiting time for bus, between when the bus comes to stop in its loading area and when the first passenger boards" (Jaiswal, Bunker, and Ferreira 2010). Jaiswal focused on a bus rapid transit (BRT) station with three loading areas (berths). He found that the mean BLTs were 4.3, 3.1, and 5.2 seconds (s) for loading areas 1,2 , and 3, respectively, while the 85 th percentile values were $7.2,4.5$, and $8.7 \mathrm{~s}$, respectively, for the aforementioned loading areas.

Jaiswal's research led to a modification in the formulation of DT, that is, accounting for BLT in the third edition of the TCQSM (TRB 2013); however, this modification only pertained to BRT stations with more than one berth. In this case the term boarding lost time was considered, which was defined as the "time spent waiting for passengers to walk to the bus door(s) from their waiting position at the stop." Thus, the formulation of DT was changed to

$$
t_{d}=t_{p f, \max }+t_{o c}+t_{b l}
$$

where $t_{d}=$ average dwell time (s); $t_{p f, \max }=$ maximum passenger flow time of all the door channels $(\mathrm{s}) ; t_{o c}=$ door opening and closing time (s), 2-5 s typical; and $t_{b l}=$ boarding lost time (s).

For stations with a single boarding area, BLT was established as $0 \mathrm{~s}$. In the case of stations with three boarding areas, a value varying between $4.0 \mathrm{~s}$ (for more crowded boarding conditions) and $4.5 \mathrm{~s}$ (for less crowded boarding conditions) was proposed. Finally, for BRT stations with two boarding areas, the analyst needs to ascertain the frequency of utilization of the second loading area and determine a value between 0 and $4 \mathrm{~s}$ (TRB 2013).

Lastly, Kathuria et al. (2016a and 2016b) emphasized that BLT should only be considered when it does not overlap with the alighting phase, thus resulting in an increase in DT. Moreover, they determined different boarding and alighting scenarios where BLT should be considered; they also studied BLT for a two-berth BRT station, reporting mean values of 1.8 and $2.4 \mathrm{~s}$ for the first and second loading areas, respectively, with 85th percentiles of 2.1 and $2.7 \mathrm{~s}$, respectively (Kathuria et al. 2016a).

This work presents a case study focused on obtaining BLT values for a two-berth off-line regular stop, considering the effect of rainy weather. The influence of weather on travel behavior has received significant attention; a review of related research was presented by Liu, Susilo, and Kariström (2017). The TCQSM indicates that "percent on-time performance may fall to low $80 \%$ range (or lower) during bad weather" and that weather influences pedestrian speed. Grisé and El-Geneidy (2017) included weather condition as a factor in the dwell time model. 
The reaction of passengers waiting at a stop when they see their desired bus differs depending on weather conditions. In the absence of rain, passengers tend to start walking toward the location where the bus is anticipated to stop as soon as they see their bus approaching. However, under rainy conditions, especially during heavy rainfall, passengers prefer to wait underneath the shelter until the bus comes to a halt, and then start walking only after identifying the exact position where the bus stops. The second scenario implies an increase in BLT. This study analyzes the effect of this behavior on BLT.

The values reported by Jaiswal (2010), Jaiswal, Bunker, and Ferreira (2010), and Kathuria et al. (2016a and 2016b) were not affected by precipitation. Both Kathuria et al. and Jaiswal, Bunker, and Ferreira considered stations where passengers are protected from rain as they move to the bus door. The research in this paper presents new findings related to the influence of rainy weather on BLT for regular bus stops with boarding predominance. This study promotes a better understanding of this phenomenon; the findings are relevant because BLT affects key parameters such as frequency, commercial speed, and travel time variability, which have been proven to significantly influence transit satisfaction (Allen, Muñoz, and Ortúzar 2019).

The remainder of this paper is organized as follows. The following section presents the case study considered in this research, followed by a description of the data collection and processing methods. Subsequently, an analysis of the data collected and the associated results are discussed. The final two sections summarize the study's conclusions and the potential scope of future research.

\section{Case Study Definition}

\section{Configuration of the Analyzed Stop}

Data from a regular bus stop at San Pedro de Mezonzo, in the city of A Coruña, Spain, were collected for the case study. The stop was selected based on a thorough analysis that involved searching for a two-berth bus stop that did not create severe interference with general traffic due to right turns and had relatively limited occurrences of illegal parking, which could invalidate the BLT data for the purpose of this study.

The bus stop at San Pedro de Mezonzo is an off-line (bay-style) far-side stop on the curbside. The length of its loading area is 25 meters, which allows for two buses to stop simultaneously (two berths). An 8 meter-long shelter accompanied by six seats protects passengers from adverse weather conditions, especially rain. However, the edge of the shelter is approximately 3 meters away from the curbside, indicating that under heavy rainfall, passengers tend to get wet while approaching a bus to board it. This positioning of the shelter has a significant influence on BLT under rainy weather conditions. The distances between the edge of the shelter's center and the doors of buses halted at typical positions in the first and second berths are approximately 5.5 and 9.5 meters, respectively.

The configuration and features of the stop are illustrated in Figures 1(a)-(d). The stop is located on a one-way street with priority at the first intersection after the stop, where no traffic light has been provided and traffic can proceed in three directions, namely straight ahead, to the right, or to the left. 


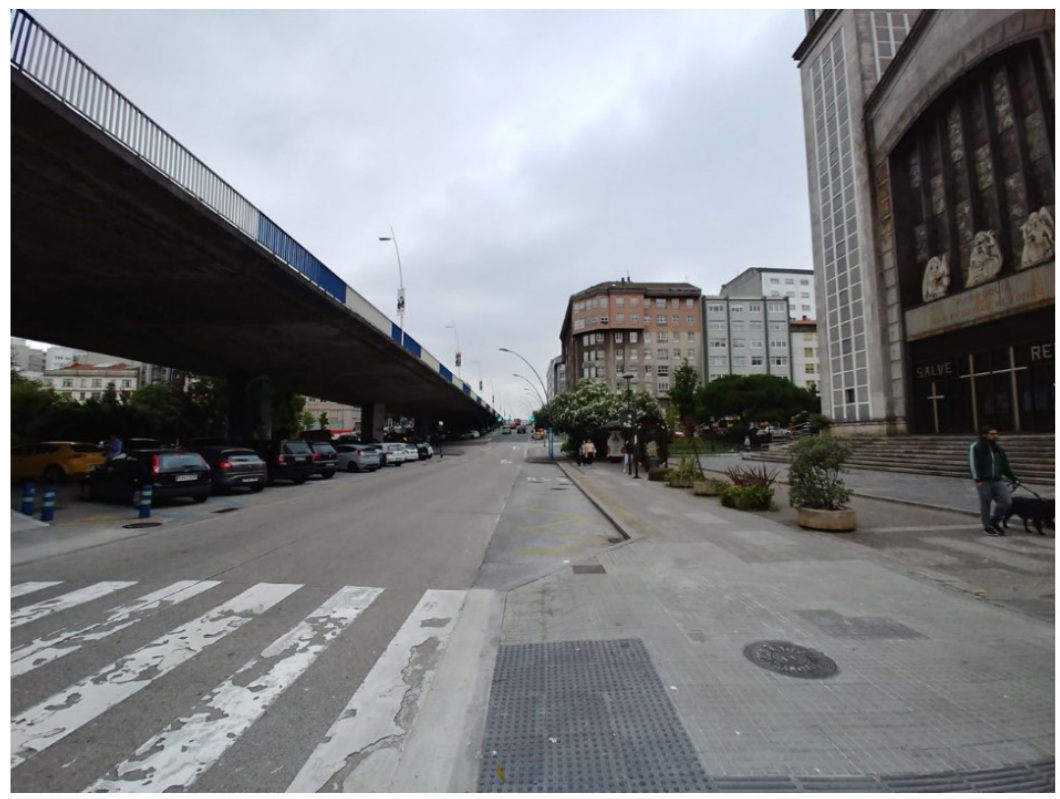

FIGURE 1(a) and (b).

General configuration and plan of bus stop at San Pedro de Mezonzo

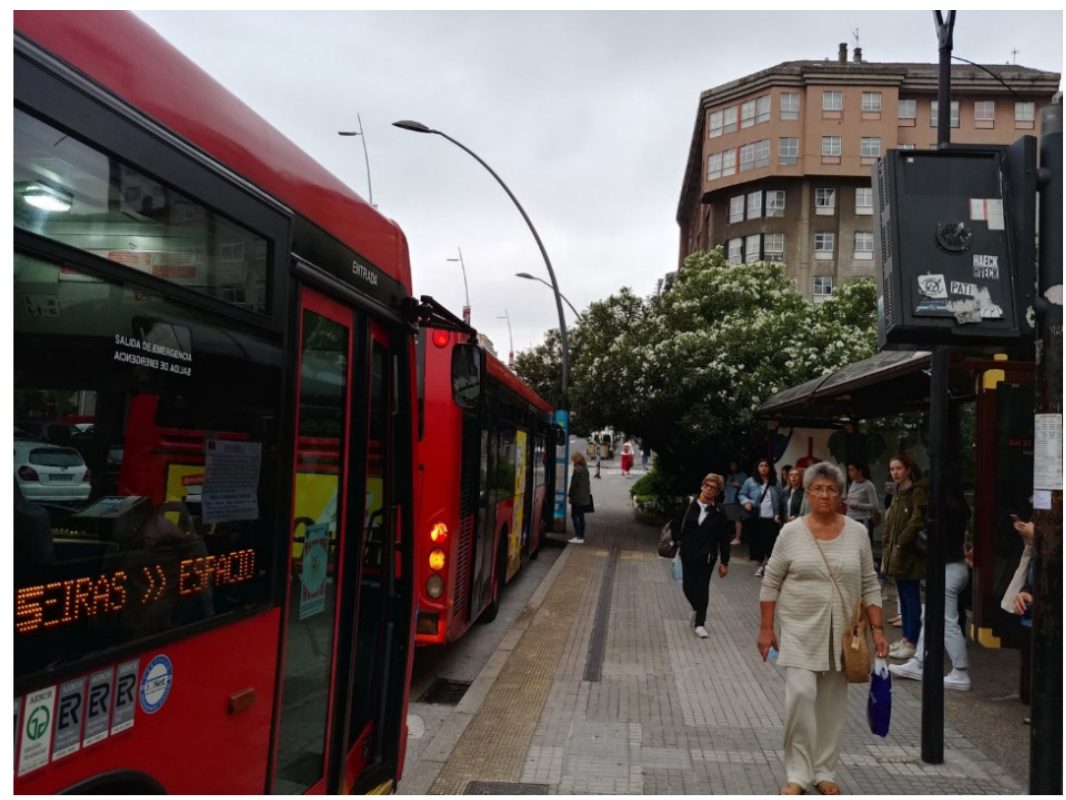

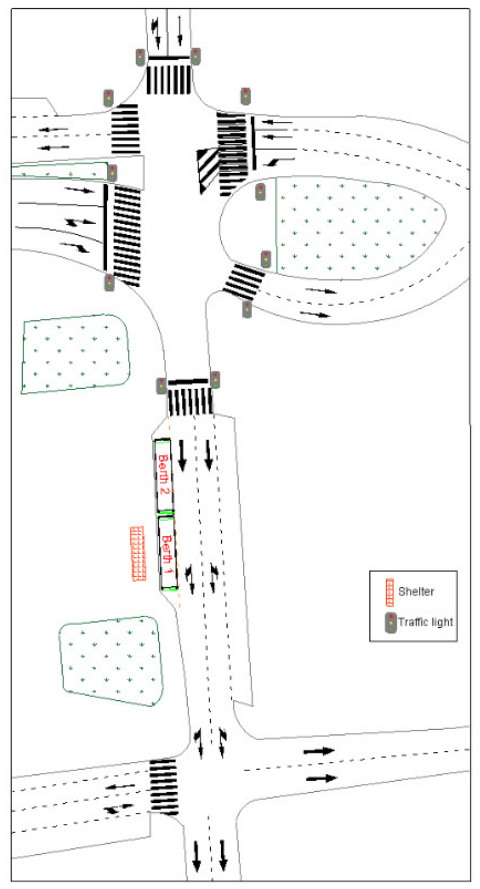

FIGURE 1(c).

Two berths in use

\section{Vehicle and Operation Characteristics}

In the study area, as well as throughout the network, buses run through mixed traffic without any preferential treatment. The services comprise five regular lines as well as one special university line (UDC), which serves as a route connecting the center of the city and the university and uses the bus stop at San Pedro de Mezonzo 
during the academic year. Moreover, the UDC exhibits a decrease in headway during the summertime. Table 1 presents the headways of each line.

\section{TABLE 1.}

Headways of Lines Using San Pedro de Mezonzo Stop

\begin{tabular}{|c|c|}
\hline Line Number & Weekday Headway (minutes) \\
\hline 4 & 12 \\
\hline 5 & 18 \\
\hline 12 & 24 \\
\hline 20 & 20 \\
\hline 24 & 30 \\
\hline UDC & $5-10^{*}$ \\
\hline
\end{tabular}

*During data collection

Passengers are expected to board the bus through the front door and alight through the rear door(s) only. In terms of the fare, passengers can use smart card payments with validation while boarding, although payment to the driver with small bills is also accepted.

A total of 126,674 buses used this stop in 2018, including both rigid buses with two or three double doors and articulated buses with three double doors. All the buses were equipped with almost-level boarding and alighting (Figure 1d), with some of them using a kneeling device.

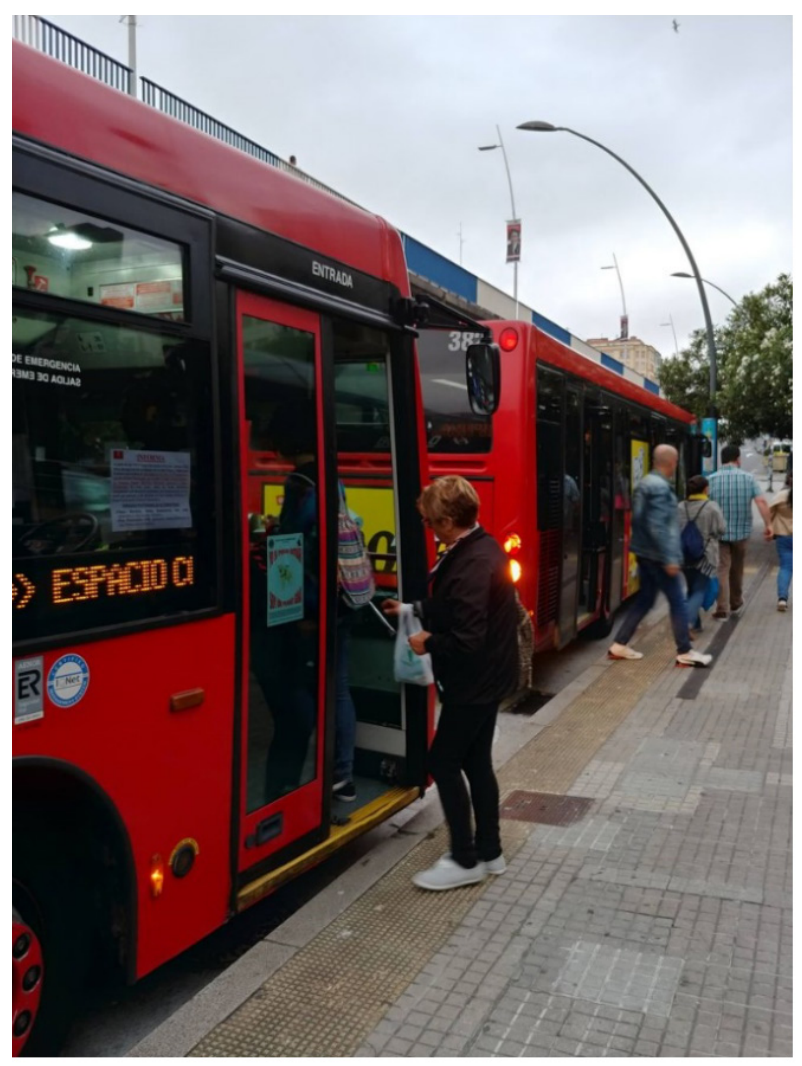

FIGURE 1 (d).

Almost-level boarding and alighting 


\section{Data Collection}

Data collection was conducted by a person seated under the shelter at the stop without causing any interference in passenger movements. Recent studies on transit performance have typically relied on big data. Automatic vehicle location (AVL) and automatic passenger counter (APC) offer a considerable amount of information with wide spatial and temporal coverages and a high level of quality (Pi et al. 2018). Although archived data could help determine total DT (Bertini and El-Geneidy 2003) and reliability measures at the bus stop level (Saberi et al. 2013), such data are not valid for the purpose of this research because they do not include information regarding passenger movement. As stated by Grisé and El-Geneidy (2017), automatic data collection methods result in the loss of some details related to the dynamics of passenger activity.

\section{Time Data Collection}

The data were registered using a chronometer application on a mobile phone. Boarding lost time was measured as the time between the moment when the doors were sufficiently opened for passengers to board the bus and the moment when the first passenger had boarded. The passenger was considered to have completed boarding when his/her second foot was on the bus.

The dates for data collection were selected to allow an adequate amount of data for each rainfall intensity level (as described in subsequent sections) to be obtained. Data collection was conducted for seven days over a period of three weeks in June 2019, as detailed in Table 2.

\section{TABLE 2.}

Data Collection Dates and Number of Records Registered

\begin{tabular}{|l|c|c|}
\hline \multicolumn{1}{|c|}{ Date } & \multicolumn{1}{|c|}{ Period } & Number of Buses \\
\hline Tuesday, 06/04/2019 & From 9:36 am to $11: 26 \mathrm{am}$ & 50 \\
\hline \multirow{2}{*}{ Thursday, 06/06/2019 } & From 9:48 am to 2:21 pm & 105 \\
\cline { 2 - 3 } & From 4:32 pm to 7:15 pm & 63 \\
\hline \multirow{2}{*}{ Friday, 06/07/2019 } & From 9:05 am to 1:48 pm & 116 \\
\hline \multirow{2}{*}{ Monday, 06/10/2019 } & From 8:27 am to 1:55 pm & 142 \\
\cline { 2 - 4 } & From 4:06 am to 6:21 pm & 50 \\
\hline \multirow{2}{*}{ Thursday, 06/13/2019 } & From 9:50 am to $11: 38 \mathrm{am}$ & 49 \\
\hline \multirow{3}{*}{ Tuesday, 06/18/2019 } & From 7:40 pm to 9:19 pm & 51 \\
\cline { 2 - 4 } & From 2:33 pm to 5:47 pm & 74 \\
\hline \multirow{2}{*}{ Wednesday, 06/19/2019 } & From 11:32 am to 12:14 pm & 19 \\
\cline { 2 - 3 } & From 1:03 pm to 1:39 pm & 15 \\
\hline
\end{tabular}

In this manner, data from 734 buses were registered. Although it is typical to obtain travel data on Tuesdays, Wednesdays, and Thursdays (USDOT 1996), the authors had verified that there were no disparities in the mean BLT with regard to the day of the week, based on data collected for the "no rain" scenario. 


\section{Rainfall Intensity Data Collection}

Considering that this research aimed to study the influence of rainy weather on BLT, it was necessary to include information regarding rainfall intensity for each data record. The city of A Coruña has three government-owned regional weather stations that register precipitation, wind, and temperature data every 10 minutes. However, as precipitation is an extremely local phenomenon and considering that all these weather stations are located more than $2 \mathrm{~km}$ away from the San Pedro de Mezonzo bus stop, the precipitation records from these weather stations could not be used to determine the level of rainfall at the bus stop. Moreover, it was observed on several occasions during data collection that the precipitation records for the three stations were $0 \mathrm{~mm} / \mathrm{h}$, although it was actually raining at the bus stop. Events such as downpours could also occur over short periods of time, which would make the typical 10-minute recording of rainfall data unfeasible for analyses.

For this study, information on the rainfall conditions during the few seconds that elapsed between the approach of the bus and passenger boarding was required. Therefore, it was necessary to establish a specific precipitation record while registering associated data; to this end, rainfall intensity was classified into the following levels:

\section{Level 0 - No Rain}

Level 1 - Drizzle: It was difficult to determine whether rainfall had occurred. Most people did not consider opening their umbrellas.

Level 2 - Light Rain: Rainfall was confirmed, although passengers were not drenched. Except for a few, most people opened their umbrellas.

Level 3 - Moderate Rain: The rainfall was bothersome, and people outside the coverage of the shelter were drenched after a short period of time. People used their umbrellas, and everyone sought shelter from the rainfall.

Level 4 - Heavy Rain: The rainfall was intense, and people outside the coverage of the shelter were completely drenched. Most pedestrians ceased their movements temporarily to take shelter and waited for the precipitation to subside.

Although levels 1 to 4 can be considered subjective, efforts were made to define them based on the clearly recognizable behaviors of people. Furthermore, data collection was conducted by a single person, which guaranteed a degree of consistency within the data.

\section{Data Cleansing}

Once data collection was completed, a data cleansing process was employed whereby unusual records, such as those inconsistent with the phenomenon being studied, were deleted. These records corresponded to the following situations:

- Initially the bus halted behind a preceding bus but did not open the doors. Once the preceding bus had departed the stop, this bus relocated and opened its doors. This scenario leads to passengers walking back and forth over the sidewalk and higher values of BLT.

- An illegally parked car in a prohibited zone at the stop hindered access to the bus from the bay, forcing the bus to stop on the carriageway.

- Other unexpected incidences that increased BLT, such as children straying from their parents immediately before boarding, thereby causing a delay. 
Circumstances that augmented the value of BLT and were associated with regular system use were considered valid and retained in the database. These included instances of passengers boarding the bus with a foldable shopping cart (or a similar object).

After data cleansing, 16 buses were excluded from the dataset and 718 buses were retained.

\section{Analyses}

\section{Description of the Sample}

Descriptive statistics of the sample are presented in Table 3, which groups data according to the berths and shows all rainfall intensity levels. A total of 576 data points were registered for Berth 1 and 142 for Berth 2 . The maximum value of BLT for Berth 1 was $6.94 \mathrm{~s}$; however, there were only six values exceeding $5.1 \mathrm{~s}$ for this berth, which corresponded to situations of heavy rainfall or passengers boarding with foldable shopping carts (or similar objects). No passenger with an object of this type was detected for rainy weather; in other words, such passengers were only noted during the no-rain situation. In the case of Berth 2, the maximum BLT was $6.48 \mathrm{~s}$, with only four values exceeding $5.1 \mathrm{~s}$, corresponding to situations of heavy (two cases), moderate (one case), and light (one case) rainfall.

\section{TABLE 3.}

BLT Descriptive Statistics with Data Grouped by Berth for All Rainfall Levels

\begin{tabular}{|c|c|c|c|c|c|c|c|c|c|c|}
\hline Berth & Rain Intensity & Count & Mean & SD & CV & Min & $25 \%$ & $50 \%$ & $75 \%$ & $\operatorname{Max}$ \\
\hline \multirow{5}{*}{1} & 0 - no rain & 358 & 2.32 & 0.77 & 0.33 & 0.89 & 1.84 & 2.17 & 2.64 & 6.94 \\
\hline & 1 -drizzle & 50 & 2.44 & 0.53 & 0.22 & 0.86 & 2.16 & 2.51 & 2.76 & 4.18 \\
\hline & 2 - light rain & 90 & 2.91 & 0.62 & 0.21 & 1.03 & 2.59 & 3.02 & 3.21 & 4.26 \\
\hline & 3 - moderate rain & 43 & 3.42 & 0.57 & 0.17 & 2.41 & 3.01 & 3.41 & 3.66 & 4.89 \\
\hline & 4 - heavy rain & 35 & 3.96 & 0.65 & 0.16 & 2.92 & 3.55 & 3.89 & 4.25 & 5.56 \\
\hline \multirow{5}{*}{2} & 0 - no rain & 93 & 2.77 & 0.80 & 0.29 & 0.93 & 2.31 & 2.78 & 3.23 & 4.67 \\
\hline & 1 -drizzle & 10 & 3.01 & 0.85 & 0.28 & 2.25 & 2.50 & 2.77 & 2.96 & 4.86 \\
\hline & 2 - light rain & 19 & 3.50 & 0.85 & 0.24 & 2.08 & 2.78 & 3.48 & 4.09 & 5.39 \\
\hline & 3 - moderate rain & 10 & 4.28 & 1.04 & 0.24 & 2.30 & 3.95 & 4.18 & 4.63 & 6.48 \\
\hline & 4 - heavy rain & 10 & 4.81 & 0.65 & 0.14 & 3.50 & 4.67 & 4.80 & 5.08 & 6.02 \\
\hline
\end{tabular}

SD - Standard Deviation, CV - Coefficient of Variation, Min - Minimum, Max - Maximum

For Berth 1, the distribution of data with respect to rainfall intensity ranged from 358 data points for level 0 (no rain) to 35 for level 4 (heavy rain). For both levels 3 and 4, the sample sizes were relatively small. In the case of Berth 2, there were 93 data points for the no-rain condition, while the number varied between 10 and 19 for levels 1 (drizzle) to 4 (heavy rain). These latter sample sizes were small; therefore, Berth 2 was not thoroughly analyzed for every rainfall condition. Nevertheless, these data points were retained in specific analyses for illustrative purposes, and they were grouped with other cases to obtain a larger sample for each analyzed category.

As shown in Table 3, each increase in rainfall level resulted in an increase of approximately $0.5 \mathrm{~s}$ in the mean BLT of Berth 1, except for level 1 (drizzle), which supports the fact that this level was practically unnoticeable. Moreover, in the absence of rain, the mean BLT was $2.32 \mathrm{~s}$ for Berth 1 and $2.77 \mathrm{~s}$ for Berth 2 . The increase in the average BLT under heavy rainfall as compared to that during an absence of rainfall (1.64 s) was significantly higher than the difference between BLTs of Berth 2 and Berth 1 in the absence of rainfall $(0.45 \mathrm{~s})$. 
The standard deviation (SD) of each intensity level for Berth 1 was between 0.53 and $0.77 \mathrm{~s}$, which yielded a coefficient of variation (CV) between 0.16 and 0.33 . The $C V$ for Berth 2 in the absence of rain was 0.29 . These $\mathrm{CV}$ values were inversely proportional to the level of rainfall for both berths. Moreover, these values indicated that the data were not dispersed significantly for each category. The equal variance statistical test for Berth 1 is detailed in a subsequent section.

As shown in Table 4, different rainfall level aggregations were created for both berths to prepare the data for statistical analysis. The mean BLT increased by approximately $1.0 \mathrm{~s}$ under noticeable rainfall as compared to the absence of (or unnoticeable) rainfall in the case of Berth 1.

\section{TABLE 4.}

BLT Descriptive Statistics with Data Grouped by Berth and Different Rainfall Level Aggregations

\begin{tabular}{|c|c|c|c|c|c|c|c|c|c|c|}
\hline Berth & Rain Intensity & Count & Mean & SD & CV & Min & $25 \%$ & $50 \%$ & $75 \%$ & Max \\
\hline 1 & $0+1+2+3+4-$ any situation & 576 & 2.60 & 0.85 & 0.33 & 0.86 & 1.99 & 2.48 & 3.04 & 6.94 \\
\hline 2 & $0+1+2+3+4-$ any situation & 142 & 3.13 & 1.02 & 0.33 & 0.93 & 2.45 & 2.94 & 3.93 & 6.48 \\
\hline 1 & $0+1-$ no (or unnoticeable) rain & 408 & 2.33 & 0.74 & 0.32 & 0.86 & 1.89 & 2.24 & 2.67 & 6.94 \\
\hline 1 & $1+2+3+4-$ any rain & 218 & 3.07 & 0.77 & 0.25 & 0.86 & 2.58 & 3.03 & 3.58 & 5.56 \\
\hline 1 & $2+3+4-$ noticeable rain & 168 & 3.26 & 0.74 & 0.23 & 1.03 & 2.84 & 3.19 & 3.72 & 5.56 \\
\hline 2 & $1+2+3+4-$ any rain & 49 & 3.83 & 1.05 & 0.28 & 2.08 & 2.78 & 3.97 & 4.66 & 6.48 \\
\hline
\end{tabular}

SD - Standard Deviation, CV - Coefficient of Variation, Min - Minimum, Max - Maximum

\section{Box Plot Comparing Berth Positions and Rainfall Intensity Levels}

Figure 2 presents a box plot of BLT with data grouped by berth and rainfall intensity level. This figure depicts the increase in BLT with rainfall level for each berth, except for the case of "drizzle" for Berth 2. Moreover, the figure reveals higher values of BLT for Berth 2 than for Berth 1.

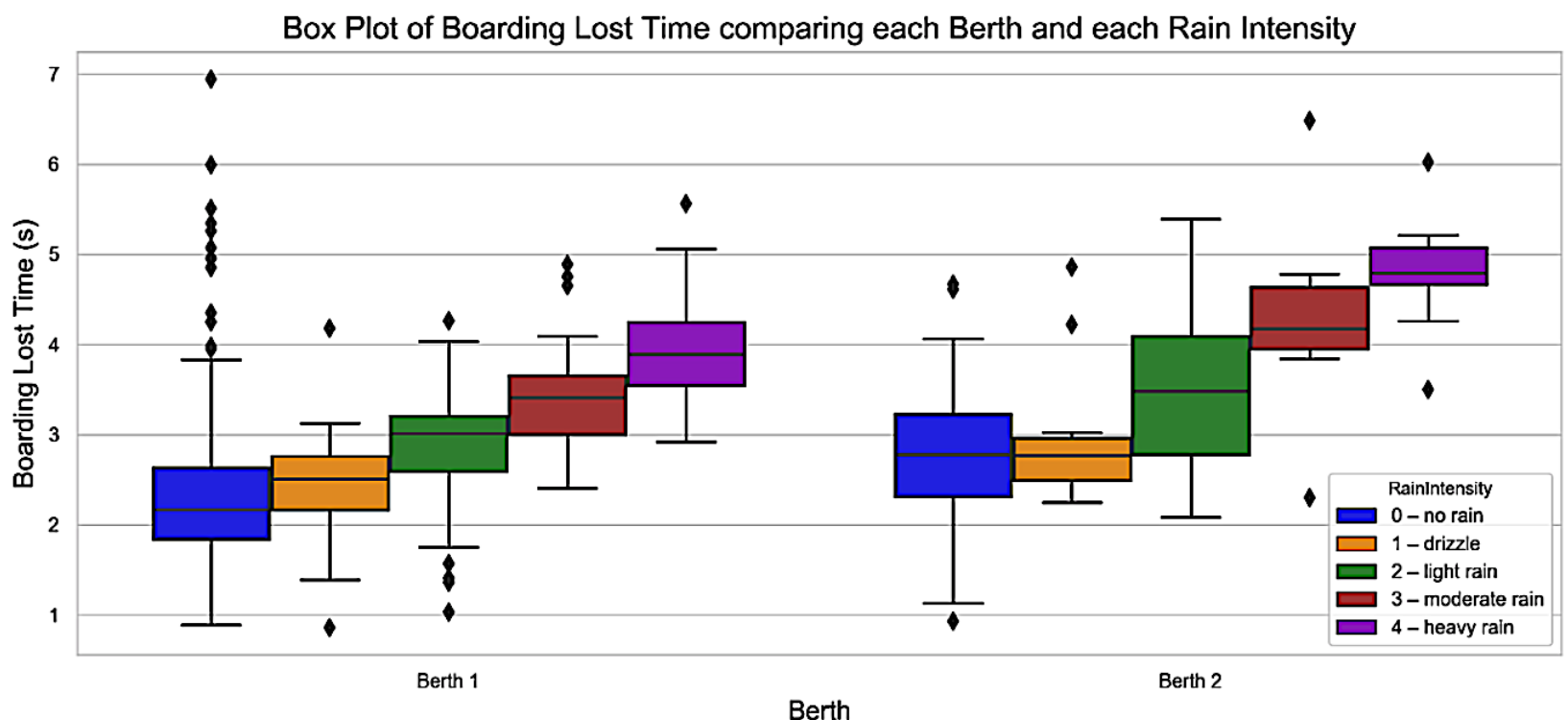

FIGURE 2.

Box plot comparing berth position and rainfall intensity levels 
In this figure, the differences between levels 0 and 1 appear to be insignificant, while they are substantial for levels 2 to 4 . The mean differences were tested through statistical analyses, as discussed in subsequent sections.

\section{Sample Histograms}

Figures 3(a)-(f) present BLT histograms of the sample with data grouped in different ways. Figures 3(a) and (b) depict histograms of BLT (number of observations for each bin) corresponding to Berths 1 and 2, respectively, considering all the data.

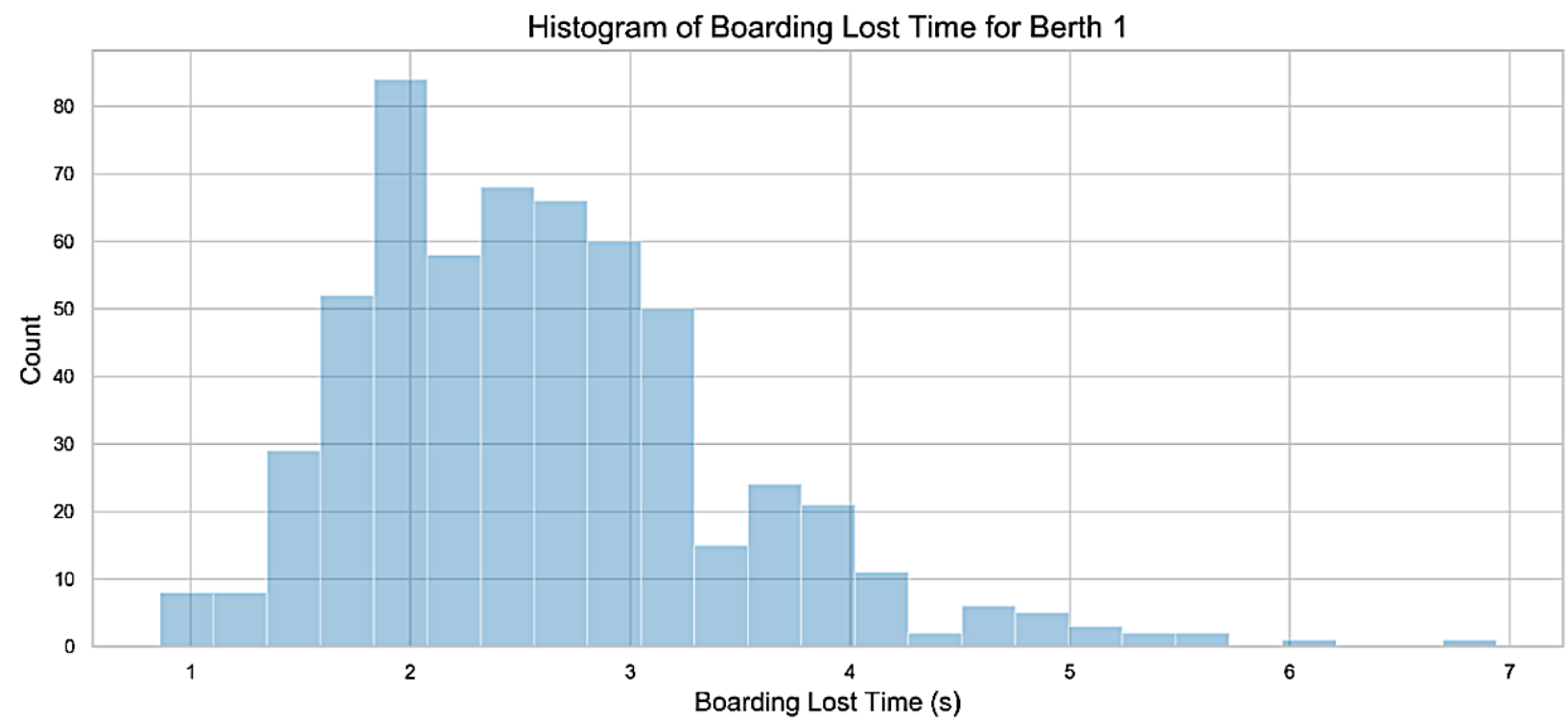

FIGURE 3(a).

Berth 1 with all data

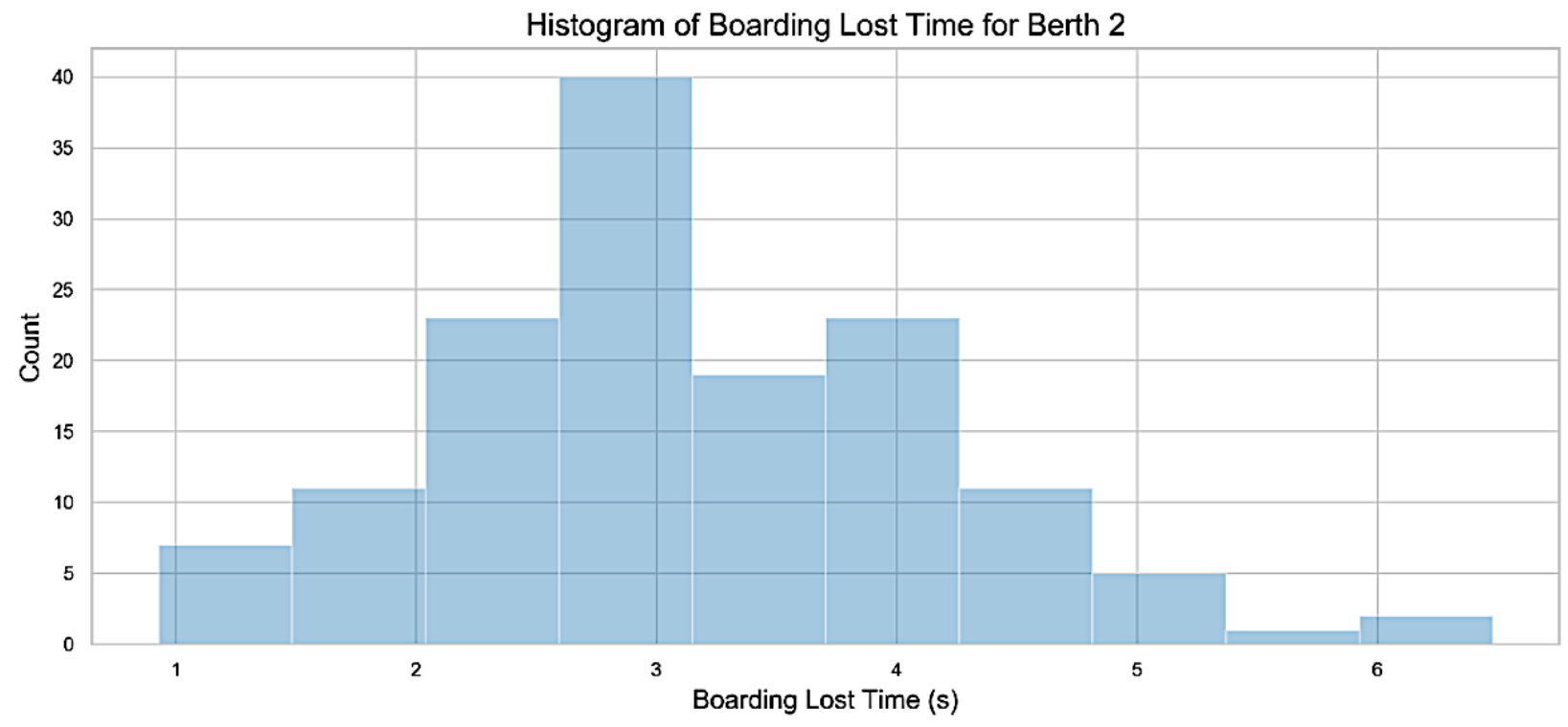

FIGURE 3(b).

Berth 2 with all data 
Figures 3(c) and (d) present histograms of BLT (density of observations) with the fit Gaussian kernel density estimate (KDE) for Berths 1 and 2, respectively. For the number of data points available and the bin widths presented, these distributions were right-skewed and could not be considered as definitely unimodal, although they appeared to be compatible with a lognormal distribution.

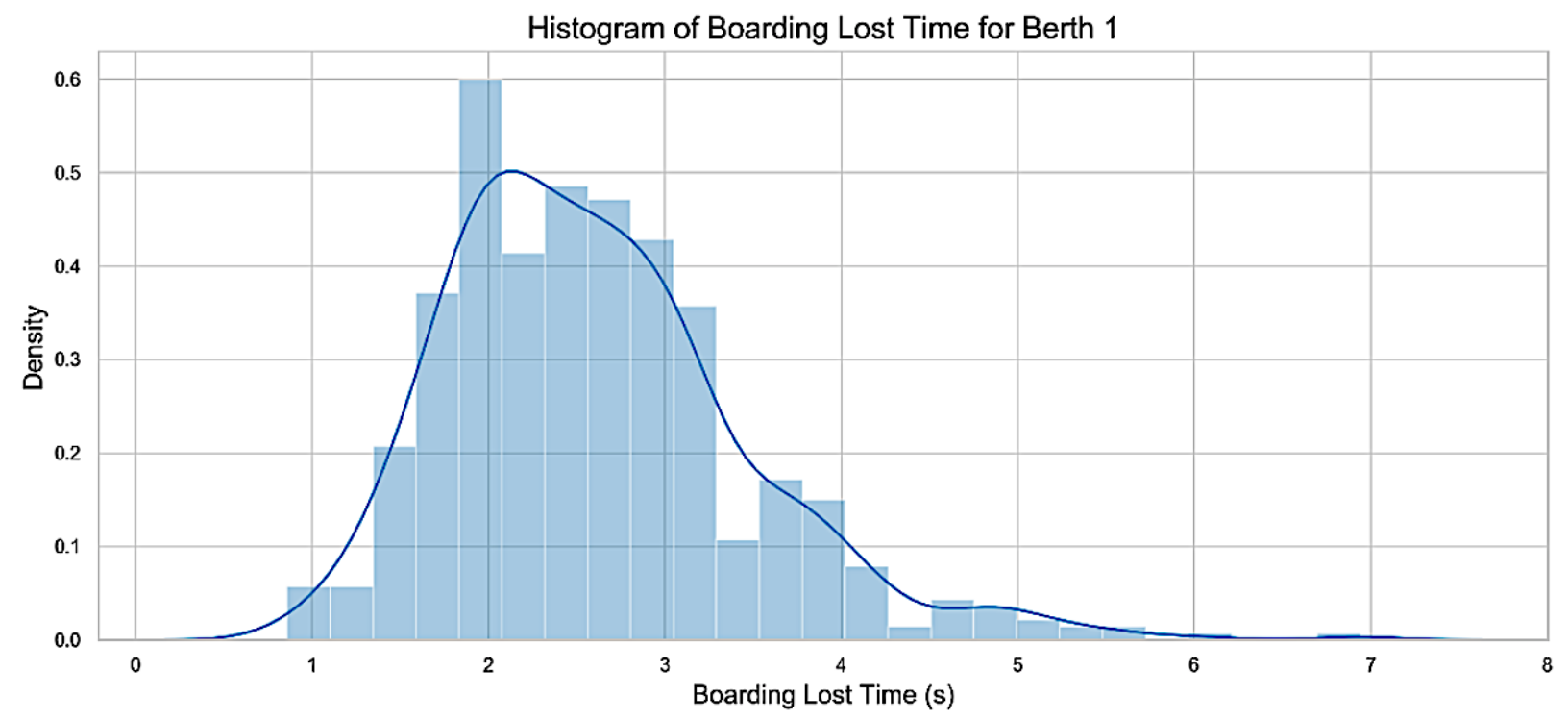

\section{FIGURE 3(c).}

Berth 1 with all data, fit to Gaussian KDE

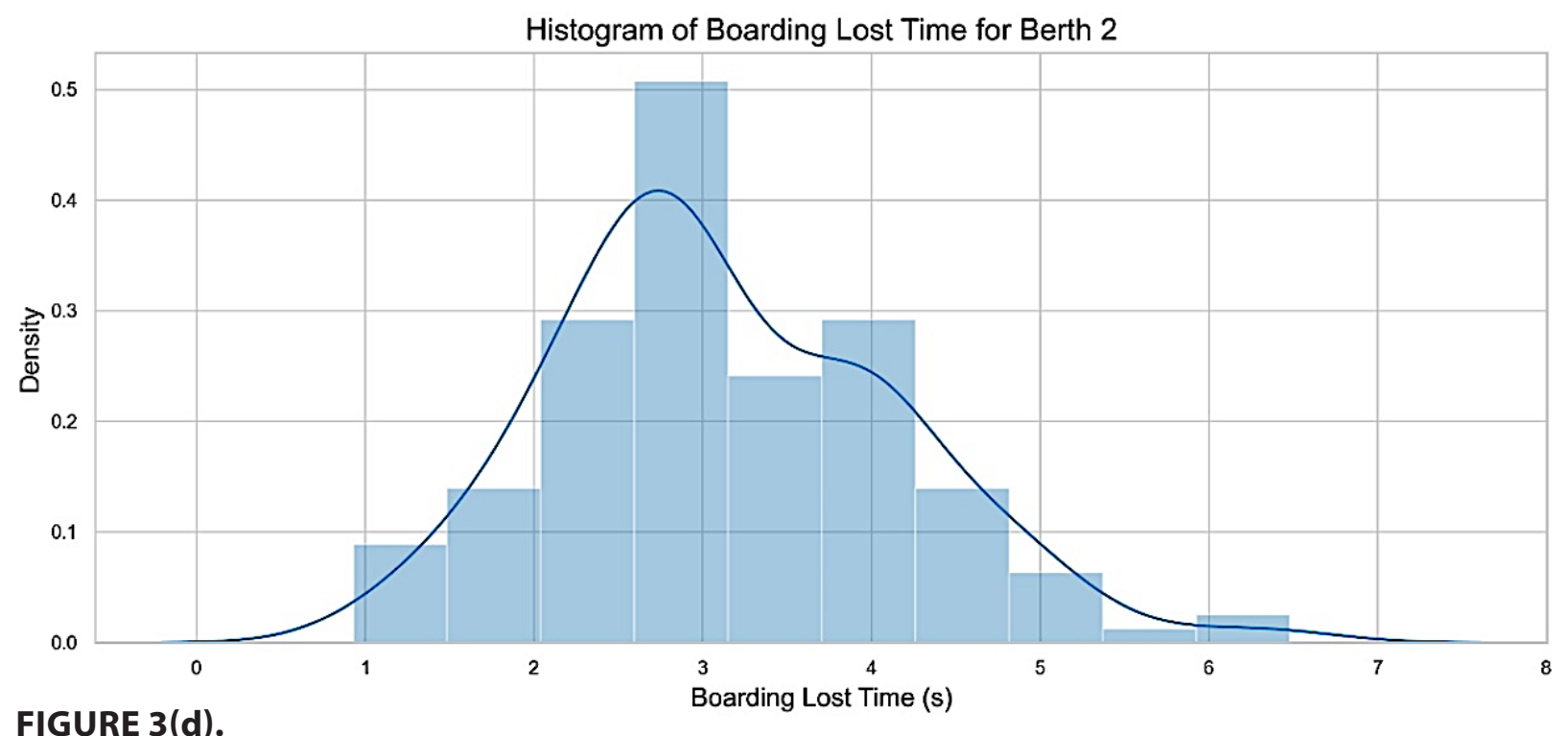

FIGURE 3(d).

Berth 2 with all data, fit to Gaussian KDE 
Figure 3(e) shows the frequency of observations for Berth 1 under each rainfall level and for Berth 2 without rain. This figure illustrates how BLT for Berth 1 shifted toward the right (i.e., increased) when the rainfall level increased. For example, BLT values for level 4 (heavy rain, purple) were generally larger than those for level 0 (no rain, blue), with values concentrated around 3-6 s for level 4 instead of $1-4 \mathrm{~s}$ for level 0 . In addition, BLT values for Berth 2 in the case of level 0 (no rain, black) varied, although they were generally higher than those for Berth 1 under no rain; most values of the latter case were lower than $3 \mathrm{~s}$, whereas a considerable percentage of data exceeded this value for the former case.

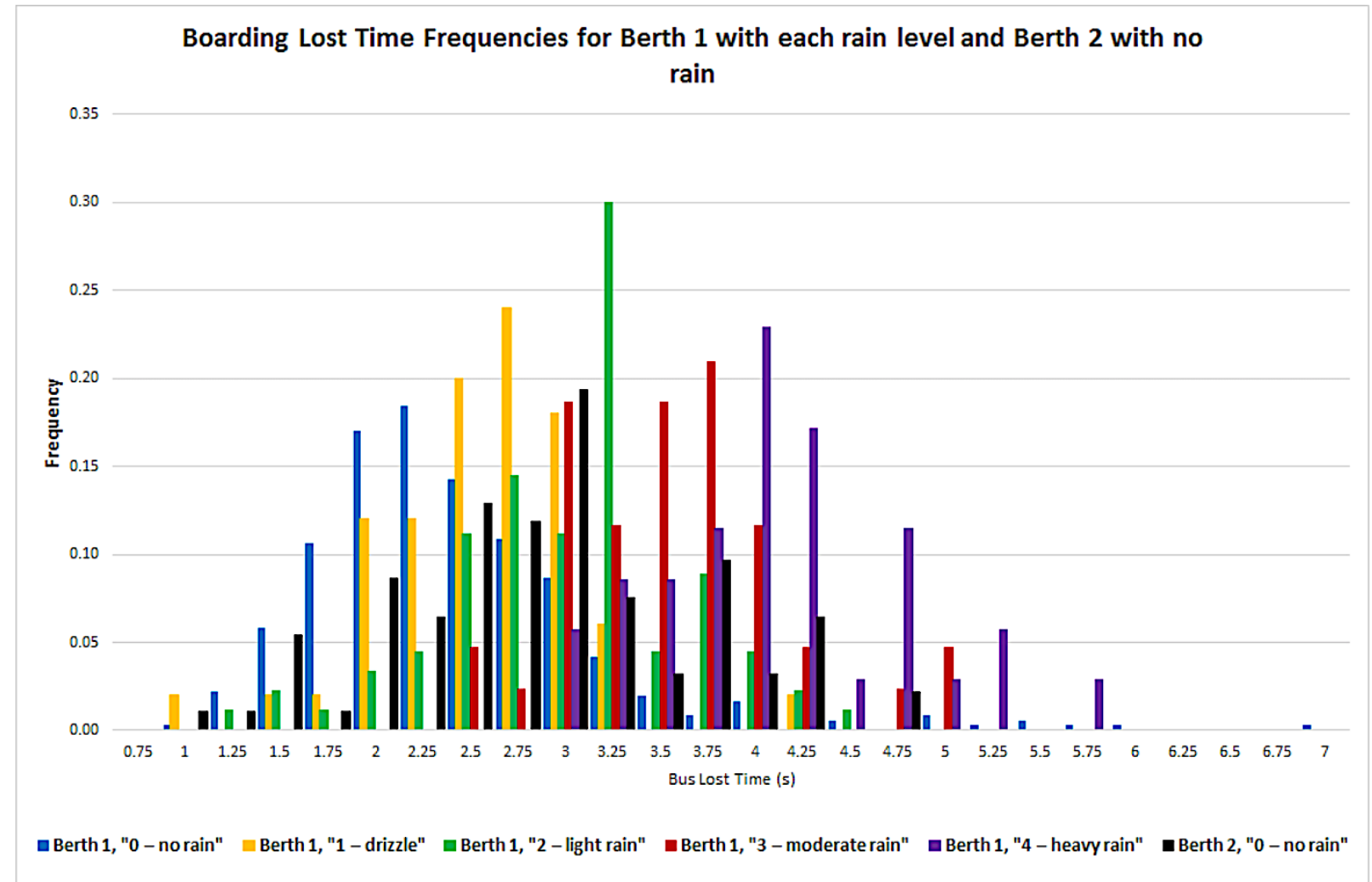

\section{FIGURE 3(e).}

Frequency of observations for Berth 1 under each rainfall intensity and Berth 2 with no rain

Figure 3(f) presents the overlapped BLT-fit Gaussian KDE for the same cases. All of these appear to be unimodal; the right-skew was not evident except for Berth 1 in the case of no rain. For level 0 , the histogram for Berth 1 appeared compatible with a lognormal distribution, whereas for Berth 2 it appeared similar to a normal distribution. The fitting of these distributions to normal and lognormal distributions was statistically checked in this study, although the detailed analysis is not included here. The results of this analysis prove that the hypothesis of fitting with the lognormal distribution could not be rejected at $95 \%$ when considering the aggregated data for any rainfall intensity, either for Berth 1 or Berth 2. The same was applicable for Berth 1 under the no-rain condition. In these cases, the hypothesis of the normal distribution of BLT was rejected. These results were consistent with the conclusions of previous studies in literature. For the remaining cases in Tables 3 and 4, there was a lack of adequate evidence in the data to suggest that they followed a lognormal distribution instead of a normal one. 


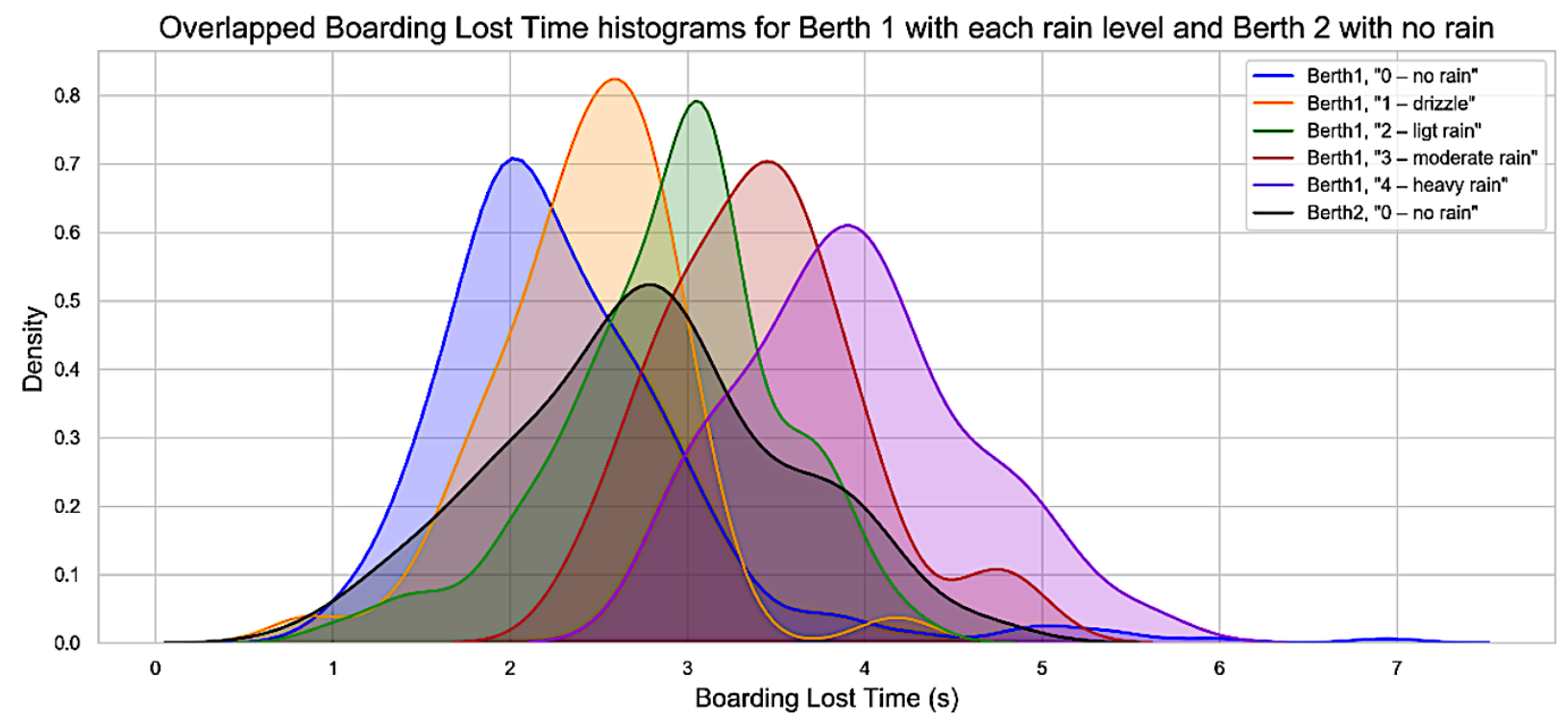

FIGURE 3(f).

Overlapped BLT-fit Gaussian KDE for Berth 1 under each rainfall intensity and Berth 2 with no rain

Similar to the box plot, the two latter figures clearly indicate the increase in BLT for Berth 1 with respect to rainfall level, and that BLT for Berth 2 exceeded BLT for Berth 1 in the case of no rain.

\section{Statistical Analysis of the Influence of Rainfall on BLT}

As discussed earlier, the mean values of BLT under different rainfall intensities varied. Formal statistical tests were employed to determine if these differences were significant, and the results obtained are summarized in Table 5.

\section{TABLE 5.}

Differences in Mean BLT under Different Rainfall Intensities for the Two Berths

\begin{tabular}{|c|c|c|c|c|c|}
\hline \multicolumn{4}{|c|}{ Comparison $\mu_{1}>\mu_{2}$} & \multirow{3}{*}{$\begin{array}{l}\text { Equal Variance Test } 95 \% \\
\text { two tailed H0: } \sigma_{1}^{2}=\sigma_{2}^{2}\end{array}$} & \multirow{3}{*}{$\begin{array}{l}\text { Equal Mean Test } 95 \% \\
\text { one tailed H0: } \mu_{1}=\mu_{2}\end{array}$} \\
\hline \multicolumn{2}{|r|}{ Variable 1} & \multicolumn{2}{|r|}{ Variable 2} & & \\
\hline Berth & Rainfall Intensity & Berth & Rainfall Intensity & & \\
\hline 2 & 0 - no rain & 1 & 0 - no rain & Accept Ho & Reject H0 \\
\hline \multirow{4}{*}{1} & 1 - drizzle & 1 & 0 - no rain & Reject H0 & Accept H0 \\
\hline & 2 - light rain & & 1 -drizzle & Accept H0 & Reject $\mathrm{HO}$ \\
\hline & 3 - moderate rain & & 2 - light rain & Accept HO & Reject Ho \\
\hline & 4 - heavy rain & & 3 - moderate rain & Accept HO & Reject Ho \\
\hline 1 & $1+2+3+4-$ any rain & 1 & 0 - no rain & Accept H0 & Reject H0 \\
\hline 1 & 2 - light rain & 1 & $\begin{array}{c}0+1-\text { no } \\
\text { (or unnoticeable) rain }\end{array}$ & Reject Ho & Reject $\mathrm{H} 0$ \\
\hline 1 & $\begin{array}{c}2+3+4-\text { noticeable } \\
\text { rain }\end{array}$ & 1 & $\begin{array}{c}0+1-\text { no (or } \\
\text { unnoticeable) rain }\end{array}$ & Accept $\mathrm{H} 0$ & Reject H0 \\
\hline 2 & $\begin{array}{l}0+1+2+3+4- \\
\text { any situation }\end{array}$ & 1 & $\begin{array}{l}0+1+2+3+4- \\
\text { any situation }\end{array}$ & Reject Ho & Reject Ho \\
\hline 2 & $1+2+3+4-$ any rain & 1 & $1+2+3+4-$ any rain & Reject H0 & Reject H0 \\
\hline
\end{tabular}


In all the cases, it was assumed that the mean estimator followed a normal distribution. For small samples, the fitting was verified; for larger samples, asymptotic normality was assumed based on the central limit theorem. The equal variance test was used to determine whether the $t$-test or the Welch test should be applied. Table 5 shows the appropriate contrast results.

For Berth 1, the results indicate a significant increment in the means for increasing rainfall levels, except for the case when changing from no rain to drizzle. Under rainfall level aggregations, all differences in the mean were significant. For level 0 and all level aggregations, the mean BLT for Berth 2 was always significantly higher than for Berth 1.

The confidence intervals for different rainfall levels and both berths are shown in Figure 4. In Figure 4(a), the leftmost case illustrates a comparison of the mean BLT interval between the two berths in the absence of rainfall; the following cases show a comparison between the mean BLT for Berth 1 under each rainfall intensity with the previous case. For example, the rightmost case illustrates the mean BLT interval for heavy rain (green) compared with moderate rain (blue). Figure 4(b) presents a comparison between the two berths for no rain (left), all rainfall conditions combined (right), and all data without discrimination based on rainfall (center).

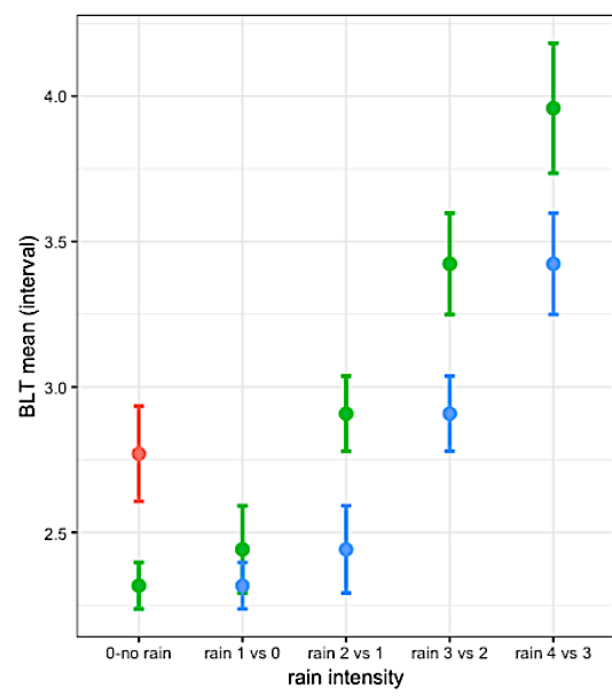

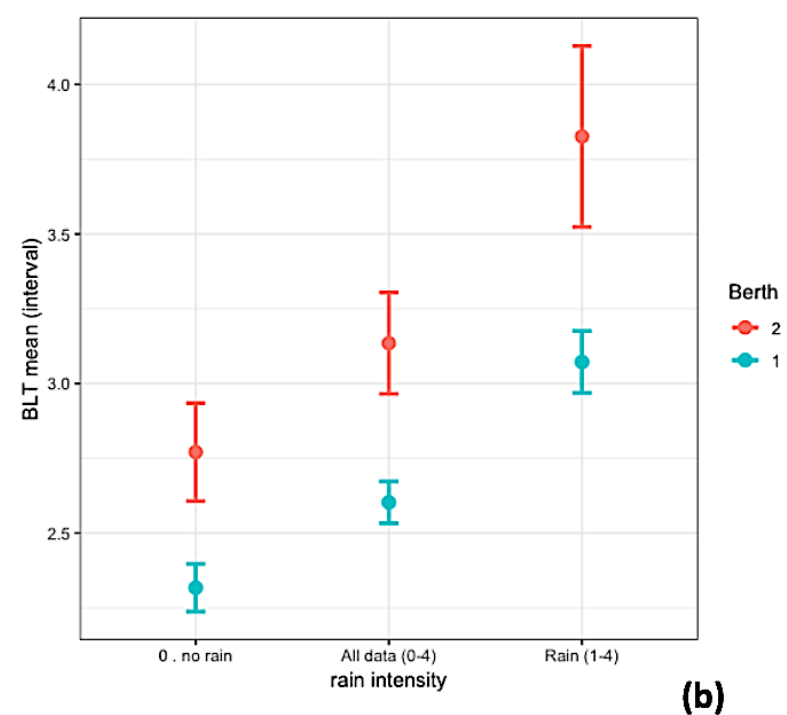

\section{FIGURE 4.}

(a)

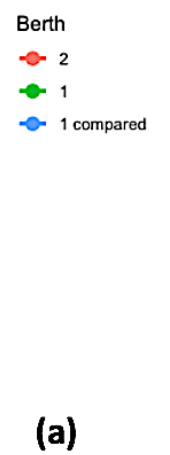

Comparison of BLT confidence intervals for Berths 1 and 2

These results indicate that the influence of rainfall on BLT should be considered to accurately calculate bus stop capacities or simulate transit systems subjected to such conditions. In the case of Berth 1 , the differences in the mean BLTs for each intensity of noticeable rainfall were $0.59 \mathrm{~s}$ (level 2 versus level 0 ), $0.52 \mathrm{~s}$ (level 3 versus level 2), and $0.53 \mathrm{~s}$ (level 4 versus level 3). These values yield a total difference of $1.64 \mathrm{~s}$ between the cases of heavy rainfall and no rainfall. Based on a binary analysis of noticeable rainfall (levels 2-4) versus no (or unnoticeable) rainfall (levels $0-1$ ), the difference was $0.93 \mathrm{~s}$ for Berth 1 and $1.24 \mathrm{~s}$ for Berth 2 . The rounded values to be considered for bus stops (with a configuration analogous to the one in this case study) were proposed and are explained in the following section. 
The mean value of BLT for Berth 1 under no rain was $2.32 \mathrm{~s}$, while Kathuria et al. (2016a) obtained a BLT of $1.8 \mathrm{~s}$ for their configuration. The difference between BLTs of Berths 1 and 2 was $0.45 \mathrm{~s}$, whereas Kathuria et al. (2016a) reported this difference to be $0.6 \mathrm{~s}$. This increment in BLT for different loading areas was less than the difference between BLTs of two consecutive (noticeable) rainfall intensities.

\section{Influence on Capacity Calculations}

As discussed in previous sections, TCQSM (TRB 2013) states that DT is the time required to serve passengers at the busiest door, in addition to the time required to open and close doors and BLT. According to the results presented in the previous section, an increase in BLT of up to $1.64 \mathrm{~s}$ should be considered due to the effect of rainfall. In general, the influence of this additional time on the line capacity would not be high; however, this inclusion enables a more precise estimation and may lead to an adequate adaptation of bus scheduling under rainy weather conditions.

Compared to the default values prescribed by TCQSM, this increase in BLT under the influence of rainfall was similar to the additional DT caused by an additional "no fare payment" passenger ( $1.75 \mathrm{~s})$ and more than a third of the BLT value suggested for a stop with three boarding areas for less crowded waiting conditions ( $4 \mathrm{~s}$ ). If the influence of rain on DT is not considered, it can be included in the general DT variability and in the operating margin. Nevertheless, the values presented herein should help analysts consider the influence of rainfall when determining the expected average DT under an anticipated combination of rainfall conditions.

At the bus stop level, changes in loading area capacity are not extremely significant; however, they are not irrelevant according to TCQSM. Considering a simple example of an off-line stop located downtown and away from signal influences, the change in loading area capacity (buses/hour) due to the addition of $1.64 \mathrm{~s}$ to DT value was $2.4 \%$. This value was obtained considering an average DT of $30 \mathrm{~s}$ with a coefficient of variation of $0.6, \mathrm{a}$ bus stop failure rate of $10 \%$, and a clearance time of $15 \mathrm{~s}$.

The impact can also be evaluated at the transit line level. To this end, a typical line in A Coruña was considered as an example; the cycle length was $15 \mathrm{~km}$, with 44 stops and a total operation time of 55 minutes. Assuming that $60 \%$ of the stops involve dominant boarding, an addition of $1.64 \mathrm{~s}$ per stop represents an increase of $1.3 \%$ in the operational time. This increment can be absorbed into the terminal times; however, under heavy rainfall, it is highly probable that traffic delays also increase the total operational time. It should be noted that this study only considers a part of the overall effects of rainfall, although this DT change can be considered to improve the accuracy of capacity calculations.

\section{Conclusions}

The main conclusion of this study is that BLT increases by $0.5 \mathrm{~s}$ for each intensity between an absence of rain, light rain, moderate rain, and heavy rain in the case of Berth 1 . This value was higher than the BLT difference between the two berths under dry weather $(0.45 \mathrm{~s})$. When considering noticeable rain versus no (or unnoticeable) rain, an increase of approximately $1 \mathrm{~s}$ should be applied to the BLT of Berth 1 under noticeable rain situations. In the absence of rainfall, the BLT of Berth 2 should be incremented by $0.5 \mathrm{~s}$ in relation to Berth 1 , whereas this increase should be $0.75 \mathrm{~s}$ for any rainfall intensity (i.e., levels $1-4$ ).

It is important to note that these values of BLT should only be considered for regular bus stops with boarding predominance; for alighting dominant stops, this time overlaps with the alighting phase and consequently does not increase DT. In addition, BLT values under rainy weather conditions are significantly affected by the distance a passenger needs to traverse from the edge of the shelter to board the bus. This aspect should be carefully 
considered, and the values proposed herein should only be applied to stops with configurations similar to the one in the case study (i.e., a regular bus stop with two berths and a similar shelter position).

For the purposes of simulation, lognormal distributions may be assumed for Berth 1 if the data are not stratified by rainfall intensity. When categorizing the data with respect to rainfall intensity, it is recommended to apply a lognormal distribution for Berth 1 in the absence of rainfall (standard situation) and normal distributions for Berth 2 in the absence of rainfall and Berth 1 for each rainfall intensity. For normal distributions, a truncated or censured normal can be utilized to avoid negative BLT values.

\section{Future Work}

In future research, several aspects can be studied:

- A thorough analysis of the influence of rainy weather on BLT for Berth 2 in this case study.

- An analysis of BLT conducted using rain data registered in situ with an accurate device, which would help eliminate subjectivity.

- The influence of rainy weather on BLT at stops with a single loading area. Although TCQSM (TRB 2013) states that BLT is zero for such cases, the results of the study indicate that this might not be the case under rainy weather conditions with a similar shelter position, where the BLT values would be similar to those for Berth 1.

- The influence of bus stop crowding on BLT under rainy weather conditions should be evaluated. This aspect was not considered in this study because this bus stop did not experience crowded situations.

- The effects of different passenger profiles such as age, sex, or physical condition on BLT both with and without rainfall should be elucidated.

- Where possible, BLT should be assessed based on traffic camera video recordings.

\section{Acknowledgments}

This study is part of the research project "Experimental analysis and modeling of the influence of stops, transfers, and right-of-way in bus systems," reference RTI2018-097924-B-I00 MCIU/AEI/FEDER, UE.

The authors thank Compañía de Tranvías de La Coruña (city bus operator) for providing access to its AVL data.

\section{References}

Allen, J., J. C. Muñoz, and J. de D. Ortúzar. 2019. "On the Effect of Operational Service Attributes on Transit Satisfaction.” Transportation 47: 2307-36. doi: 10.1007/s11116-019-10016-8.

Bertini, R. L., and A. El-Geneidy. 2003. "Generating Transit Performance Measures with Archived Data." Transportation Research Record: Journal of the Transportation Research Board 1841 (1): 109-19. doi:10.3141/1841-12.

Dueker, K. J., T. J. Kimpel, J. G. Strathman, and S. Callas. 2004. “Determinants of Bus Dwell Time." Journal of Public Transportation 7 (1): 21-40. doi:10.5038/2375-0901.7.1.2.

Grisé, E., and A. El-Geneidy. 2017. "Identifying the Bias: Evaluating Effectiveness of Automatic Data Collection Methods in Estimating Details of Bus Dwell Time." Transportation Research Record: Journal of the Transportation Research Board 2647 (1): 33-40. doi:10.3141/2647-05. 
Jaiswal, S. 2010. "Busway Platform Bus Capacity Analysis". PhD diss., Queensland University of Technology.

Jaiswal, S., J. M. Bunker, and L. Ferreira. 2010. "Modelling Bus Lost Time: An Additional Parameter Influencing Bus Dwell Time and Station Platform Capacity at a BRT Station Platform." Presentation at Transportation Research Board 89th Annual Meeting, Washington, DC.

Kathuria, A., M. Parida, Ch. R. Sekhar, and M. Pathak. 2016a. "Examining Bus Dwell Time and Bus Lost Time Dynamics for a Bus Rapid Transit System." Presentation at Transportation Research Board 95th Annual Meeting, Washington, DC.

Kathuria, A., M. Parida, Ch. R. Sekhar, and M. Pathak. 2016b. "Examining Bus Lost Time Dynamics for a Bus Rapid Transit Station." Journal of Public Transportation 19 (2): 168-82. doi:10.5038/2375-0901.19.2.10.

Levinson, H. S. 1983. "Analyzing Transit Travel Time Performance." Transportation Research Record 915: 1-6.

Liu, C., Y. O. Susilo, and A. Karlström. 2017. "Weather Variability and Travel Behaviour - What We Know and What We Do Not Know." Transport Reviews 37 (6): 715-41. doi:10.1080/01441647.2017.1293188.

Muzyka, A. 1975. "Bus Priority Strategies and Traffic Simulation.” In Better Use of Existing Transportation Facilities, Transportation Research Board Special Report 153, edited by M. Moore, 39-49. Washington DC: National Research Council.

Pi, X., M. Egge, J. Whitmore, A. Silbermann, and Z. S. Qian. 2018. “Understanding Transit System Performance Using AVL-APC Data: An Analytics Platform with Case Studies for the Pittsburgh Region." Journal of Public Transportation 21 (2): 19-40. doi:10.5038/2375-0901.21.2.2.

Saberi, M., A. K. Zockaie, W. Feng, and A. El-Geneidy. 2013. "Definition and Properties of Alternative Bus Service Reliability Measures at the Stop Level." Journal of Public Transportation 16 (1): 97-122. doi:10.5038/23750901.16.1.6.

TRB (Transportation Research Board). 1985. Highway Capacity Manual, Special Report 209, Third Edition. Washington, DC.

TRB (Transportation Research Board). 2003. TCRP Report 100: Transit Capacity and Quality of Service Manual, Second Edition. Washington, DC.

TRB (Transportation Research Board). 2013. TCRP Report 165: Transit Capacity and Quality of Service Manual, Third Edition. Washington, DC.

USDOT (US Department of Transportation). 1996. Travel Survey Manual. doi:10.21949/1404543.

\section{About the Authors}

Margarita Novales (margarita.novales@udc.es) is an associate professor of transport engineering and infrastructures in the Department of Civil Engineering, University of A Coruña (Spain). She has an MS in civil engineering (University of A Coruña) and a PhD with a thesis on tram-train public transit systems, which received three awards. She is chair of the AP075(3) International Developments in Light Rail Transit Subcommittee of the Transportation Research Board (TRB) and secretary of the Foro de Ingeniería del Transporte. She has authored nearly 75 papers published in various international journals and conferences on issues related to public transit, sustainable mobility, and railway engineering. 
Alfonso Orro (alfonso.orro@udc.es) is an associate professor of transport engineering and infrastructures in the Department of Civil Engineering, University of A Coruña (Spain). He has an MS in civil engineering (University of Cantabria), a micro master's degree in supply chain management (MITx), and a PhD with a thesis on modeling of transport demand (University of A Coruña). He is currently co-director of the master's in logistics and transport. He has authored numerous papers published in various international journals and conferences on issues related to transport planning, discrete choice models, sustainable mobility, and railway engineering.

José-Benito Pérez-López (benito.perez@udc.es) is an assistant professor of statistics in the Department of Economics, University of A Coruña (Spain). He was a full-time consultant in business data analysis for 15 years, working for the Boston Consulting Group and Hewlett Packard consulting division. He majored in statistics and operational research (Complutense University of Madrid) and has an MS in mathematics, a post-graduate diploma of the PhD program in civil engineering (University of A Coruña), and a project management master's certificate (George Washington University). He is a research assistant in the Railways and Transportation Group of the School of Civil Engineering, University of A Coruña, where he has developed research projects related to discrete choice models and spatial micro-econometrics of economic statistics applied to transportation and sustainable mobility.

Jorge Feal (jorge.feal@udc.es) is a student of the civil engineering degree at University of A Coruña. He is also a trainee researcher of the Group of Railways and Transportation Engineering at the university's Department of Civil Engineering.

Miguel R. Bugarín (m.bugarin@udc.es) is a professor of railway engineering at the Department of Civil Engineering, University of A Coruña. He has an MS in civil engineering (University of Cantabria) and a PhD with a doctoral thesis on improving the geometry of high-speed turnouts by means of a railway dynamics model (University of Cantabria). He has authored numerous papers in various international journals and conferences on issues related to railway track engineering and public transit. 